\title{
A cross-sectional survey of the relationship between walking, biking, and the built environment for adults aged over 70 years
}

This article was published in the following Dove Press journal:

Risk Management and Healthcare Policy

20 April 2012

Number of times this article has been viewed

\author{
Paul Y Takahashi' \\ Mitzi A Baker ${ }^{3}$ \\ Stephan $\mathrm{Cha}^{2}$ \\ Paul V Targonski' \\ 'Primary Care Internal Medicine, \\ ${ }^{2}$ Biomedical Statistics and Informatics, \\ Mayo Clinic, ${ }^{3}$ Planning Department, \\ Olmsted County, Rochester, MN, USA
}

Purpose: Determine the relationship between walkability scores (using the Walk Score ${ }^{\circledR}$ ) and activity levels (both bicycle and walking) in adults aged between 70 and 85 years in Rochester, Minnesota.

Patients and methods: This was a self-reported cross-sectional survey in adults aged over 70 years living in Rochester, Minnesota. Analysis used $t$-tests or chi-square analysis as appropriate. The primary endpoint was bicycle use or walking. The predictor variables were the Walk Score ${ }^{\circledR}$ as determined by their address, Charlson index, Duke Activity Status Index (DASI), and a 12-item short-form survey (SF-12) scores. Secondary analysis used an outcome of functional status (using the DASI) and walkability scores.

Results: Fifty-three individuals completed the surveys (48\% return rate). The average age in the overall cohort was 77.02 years. Eighty-nine percent of individuals could walk at least a block and $15.1 \%$ rode their bicycles. The Walk Scores ${ }^{\circledR}$ did not differ between those who walked $(38.9 \pm 27.4)$ and those that $\operatorname{did} \operatorname{not}(40.0 \pm 36.08 ; P=0.93)$. In a similar fashion, the Walk Scores ${ }^{\circledR}$ were not different for those who biked $(36.38 \pm 27.68)$ and those that did not (39.44 \pm 28.49 ; $P=0.78$ ). There was no relationship between Walk Scores ${ }^{\circledR}$ and DASI; however, a decreased DASI score was associated with increased age and comorbid illness (Charlson Score).

Conclusion: In this small pilot survey, there was no difference in Walk Scores ${ }^{\circledR}$ between those older adults who walked or biked, compared to those that did not. The Walk Scores ${ }^{\circledR}$ were low in both groups, which may indicate the lack of accessibility for all older adults living in Rochester, Minnesota. The functional status seemed to be more related to age or comorbid conditions than the built environment.

Keywords: walking, biking, older adults, functional status

\section{Introduction}

Active transportation (walking and biking) is an important aspect of health and social connectedness for older adults. Olmsted County, Minnesota (MN) has an estimated population of 144,248 people, with $12.7 \%$ of that population aged over 65 years according to the 2010 Census. ${ }^{1}$ Encouraging physical activity was one of the goals of the CardioVision 2020 program for this community. This program had the explicit goal of improving the overall health of the community. ${ }^{2}$ The impact of the built environment (sidewalks and proximity to retail, recreation, and social meeting places) is an important consideration for walking or biking. Previous studies have indicated the importance of distance between walking destinations as significant for increasing walking. ${ }^{3}$ The impact of the proximity of retail outlets, recreational areas, social areas, and grocery outlets are not easily known in the older population. These findings could potentially be important for city planning and health advocacy. ${ }^{4}$
Correspondence: Paul Y Takahashi Mayo Clinic, 200 First Street SW, Rochester, MN 55905, USA

$\mathrm{Tel}+\mathrm{I} 50728425$ I I

Fax + I 5072660036

Email takahashi.paul@mayo.edu 
In other populations, the impact of the built environment upon walking has been studied and has shown some increased walking behavior in highly walkable neighborhoods. ${ }^{5}$ If one lives closer to areas of interest like stores or houses of worship, they tended to walk more. In walkable neighborhoods, individuals often use walking for transportation (walking to a location). ${ }^{6}$ Walking and biking not only are useful modes of transportation; they have well known health benefits. There is a relationship between being physically active and decreased obesity from the 2005 National Health Survey. ${ }^{7}$ There appears to be some evidence that close proximity to destinations and active transportation can be beneficial. However, it is not clear what relationship exists between the built environment, as measured by the Walk Scores $^{\circledR}$ and the frequency of walking or biking in an older population in a smaller city in MN. This question is novel because it attempts to answer this uncertainty in an older population in a lower population dense city. We used a crosssectional mailed survey of adults aged from 70 to 85 years in Rochester, $\mathrm{MN}$ as a means to determine this relationship.

\section{Methods}

\section{Study design}

This was a cross-sectional mailed survey of individuals within Rochester, MN. The study and the survey were approved by the Mayo Clinic Institutional Review Board (IRB), and the IRB reviewed and approved the survey and consent forms. The study was conducted in accordance with the principles of the Declaration of Helsinki. ${ }^{8}$

\section{Setting}

This study was a mailed survey to individuals aged 70 years and older living within Rochester, MN. Three hundred individuals over the age of 70 years were randomly selected from those individuals who had sought care at Mayo Clinic Rochester. The individuals lived within the five post office zip codes of Rochester by the last known address. These zip codes encompassed most of the city of Rochester.

\section{Survey}

The paper survey was designed for a mail in response. The questions on the survey included self-report for walking, biking, the 12-item short-form survey (SF-12) health questionnaire, and the Duke Activity Status Index (DASI). The survey was mailed to all of the 300 participants at the last known address. The survey was mailed twice to those who had not responded to the initial mailing. We used reminder phone calls after the second mailing. Initial mailings started on July 15, 2011 and ended on October 15, 2011. Second mailings occurred 1 month after the initial mailings. Data was collected, entered, and analyzed after the completion of enrollment and follow-up.

The subjects received an initial mailing with a request to mail the survey (completed or refused) back to Mayo Clinic Survey Research Center in an accompanying, self-addressed, stamped envelope. Participation was entirely voluntary and was open to all adults who met the study entry criteria. Participants were asked to read the accompanying cover letter detailing the purpose of the study, as well as the procedures for returning the completed (or refused) survey. Procedures included placing the survey in an accompanying sealed and self-addressed envelope, and returning it to Mayo Clinic. Participants who did not wish to participate indicated their refusal on the cover letter without penalty.

\section{Participants}

The participants were adults aged between 70 to 85 years living within Rochester, MN. All individuals lived independently within the community. Participants had the cognitive and reading ability to complete the survey. All participants had a Mayo Clinic registration number to allow mailing of the survey. Participants were identified based upon a random selection of individuals fitting the criteria.

\section{Exclusion}

Participants were excluded if they were out of the age range or if they lived outside of the five zip code areas. Participants who were residing in a nursing home, suffering from a clinical diagnosis of dementia, or who could not fill out the survey were also excluded. All other participants who could not provide consent were excluded.

\section{Variables}

\section{Outcome variable}

The primary outcomes were walking or bicycle use as dichotomous variables. If an individual could walk a block or more by self-report, this was considered a positive response for the study. If the subject rode a bicycle at all, this was also considered positive response. This activity level was selfdetermined from the mailed survey. A secondary outcome variable included the functional status, as measured by the DASI. ${ }^{9}$ The DASI is a 12 -question self-assessment tool to measure functional status based upon common daily activities like walking a block or two on level ground, or doing strenuous sports like swimming or singles tennis. The DASI was scored using the standardized weighting method and 
converted into metabolic equivalents. A higher score on the DASI indicated better physical function.

\section{Predictor variables}

The primary exposure variable was the environmental walkability criteria. The instrument used was the commercially available Walk Score ${ }^{\circledR}$. Walk Score ${ }^{\circledR}$ has a proprietary algorithm which was used to create a score which assessed the ease of walking from the participant's residence to a different location. The Walk Score ${ }^{\circledR}$ is based upon the address of the participant and its proximity to amenities within the region. The Walk Score ${ }^{\circledR}$ uses a weighted scoring system with amenities like restaurants within 0.25 miles receiving the highest score. The scoring ranges from $0-100$, with scores less than 50 points being considered car-dependent. The Walk Score ${ }^{\circledR}$ uses linear distance from the address of the participant and does not take into account availability of pedestrian facilities, traffic, or roads. ${ }^{10}$ It reflects the density of available destinations or amenities to a location. The Walk Score ${ }^{\circledR}$ has been validated against geographical information services (GIS) in previous studies. ${ }^{11}$

The other exposure variables included age as a potential modifier for walking as well as comorbid medical condition. A Charlson index was calculated for all participants in the survey based upon the electronic medical record. The Charlson index is a composite index of comorbid health conditions that can be used to classify prognosis. ${ }^{12}$ The Charlson index provided an overview of the medical condition of the participant. The 12-item short-form survey (SF-12) was used to collect physical and mental health measures on all the participants in the survey. This questionnaire was designed to assess the quality of life for the participants in the study with two subscales of physical health and mental health. This 12-item questionnaire compares favorably to the longer 36-item survey, which measures quality of life. ${ }^{13}$

\section{Data sources}

All of the outcome data was self-reported by the patient on the returned surveys including bicycle use, walking, the SF-12, and the DASI instrument. Details of the survey are noted above. Age was determined from the electronic medical record. The Charlson index was calculated using an administrative electronic review of the medical record for each subject in the study, based on 3 years of prior medical history. The Walk Score ${ }^{\circledR}$ was calculated based upon the address of the participant and calculated using the online calculator for scoring. ${ }^{10}$ Bias was minimized as much as possible. The largest source of bias was participation bias.
This bias was minimized by having two mailings and a phone call to improve the completion rates for the study.

\section{Study size and power}

This was an initial survey to determine the variance between the people who walked, and or rode a bike, and those who did not and the relationship of the built environment as measured by the Walk Score ${ }^{\circledR}$.

\section{Data analysis}

The primary outcome involved the relationship between the Walk Score ${ }^{\circledR}$ and walking and biking. The initial comparison of characteristics and demographics used $t$-tests for continuous variables or chi-square analysis for dichotomous variables as appropriate. These initial tests compared those who were active and those who were not. The primary outcome was a dichotomous yes or no to bicycling and walking. The analysis included a $t$-test for Walk Score ${ }^{\circledR}$. As a secondary aim, the relationship between functional status (DASI score) was regressed in a linear fashion against the Walk Score ${ }^{\circledR}$. The DASI was also regressed in a linear fashion against age and the Charlson index to verify the relationship of age and comorbid medical condition to functional status.

Initial demographics and Charlson index scores were compared between both groups (with and without walking and biking). This initial information was analyzed with $t$-tests for continuous data and with logistic regression for proportional information. All tests for significance in the primary, secondary, and demographic evaluation used a $P$ value of 0.05 as a level of significance with two tails, unless otherwise specified.

\section{Results}

Three hundred surveys were mailed out, of which 179 were not used because of address changes or mortality. Of the 121 completed surveys, 53 (43.8\%) were completed and returned (Figure 1). The average age of the cohort overall was 77.02 years \pm 4.58 years. The average Charlson score was $1.77 \pm 2.37$ in the cohort. There were no differences in age or Charlson scores between those who walked and those who did not. There were no differences in age or Charlson score between those who biked or those who did not (Table 1).

For the primary outcome of walking in this older population, 47 subjects $(88.7 \%)$ were able to walk at least a block. There was no difference in the Walk Score ${ }^{\circledR}$ between those who walked (score of $38.85 \pm 27.4$ ), and those who did not $(40.0 \pm 36.1)$. The subjects who walked had a higher SF-12 score for both emotional and physical quality of life; 


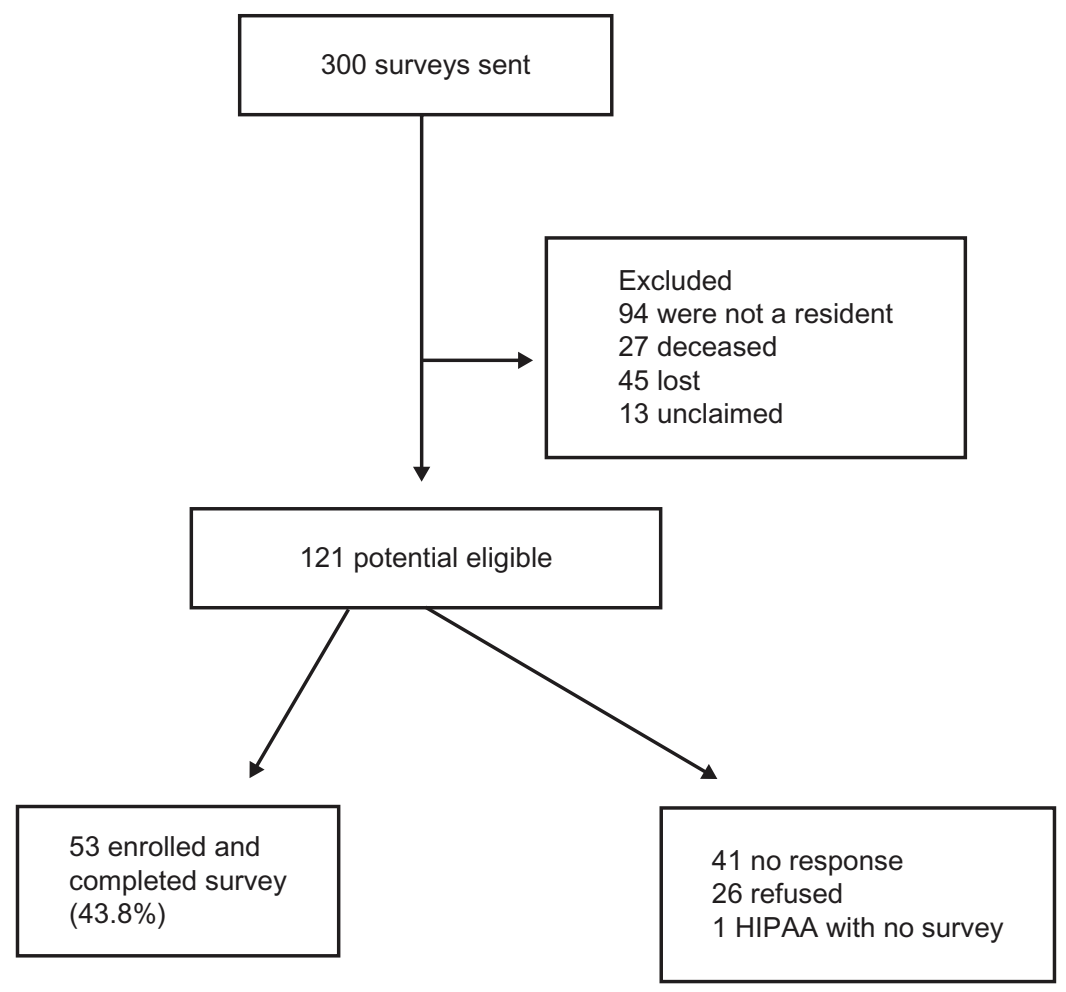

Figure I Flow diagram of 53 completed studies from 300 surveys.

Abbreviation: HIPPA, Health Insurance Portability and Accountability Act.

thus, they had a higher self-perceived quality of life. The walking group also had a higher DASI score (38.44 \pm 13.4$)$ compared to those who did not $(16.18 \pm 17.49)$. Thus, the self-reported functional status was higher in the walking group. These findings are noted in Table 2.
The use of a bicycle occurred in six subjects (11.3\%). There was no difference in Walk Score ${ }^{\circledR}$ between those who used a bicycle and those that did not. There also was no difference in the quality of life scores as noted on the SF-12 for mental or physical subsets. The DASI score was

Table I Demographic overview of entire cohort and by subgroup in adults aged 70-85 years

\begin{tabular}{|c|c|c|c|c|c|c|c|}
\hline Variable & $\frac{\text { Overall }}{(N=53)}$ & $\frac{\text { No bicycle use }}{(N=45)}$ & $\frac{\text { Bicycle use }}{(N=8)}$ & $P$ value & $\frac{\text { No walking }}{(N=6)}$ & $\frac{\text { Walk }}{(N=47)}$ & $P$ value \\
\hline Age & $77.02 \pm 4.58$ & $77.29 \pm 4.56$ & $75.5 \pm 4.75$ & 0.31 & $78.5 \pm 5.86$ & $76.83 \pm 4.44$ & 0.41 \\
\hline Charlson index & $1.77 \pm 2.37$ & $1.84 \pm 2.54$ & $1.38 \pm 1.06$ & 0.61 & $2.33 \pm 3.44$ & $1.7 \pm 2.24$ & 0.54 \\
\hline \multicolumn{8}{|l|}{ Sex, N (\%) } \\
\hline Female & $28(53)$ & $26(58)$ & $2(25)$ & 0.09 & $3(50)$ & $25(53)$ & 0.88 \\
\hline Male & $25(47)$ & $19(42)$ & $6(75)$ & & $3(50)$ & $22(47)$ & \\
\hline \multicolumn{8}{|l|}{ Race, N (\%) } \\
\hline White race & $52(98)$ & $44(98)$ & $8(100)$ & 0.67 & $6(100)$ & $46(98)$ & 0.72 \\
\hline Other race & $\mathrm{I}(2)$ & $\mathrm{I}(2)$ & $0(0)$ & & $0(0)$ & $I(2)$ & \\
\hline \multicolumn{8}{|c|}{ Marital status, N (\%) } \\
\hline Divorced & $6(11)$ & $6(13)$ & $0(0)$ & 0.63 & $\mathrm{I}(\mathrm{I7})$ & $5(11)$ & 0.4 \\
\hline Married & $38(72)$ & $31(69)$ & $7(88)$ & & $3(50)$ & $35(74)$ & \\
\hline Single & $2(4)$ & $2(4)$ & $0(0)$ & & $0(0)$ & $2(4)$ & \\
\hline Widowed & $7(13)$ & $6(13)$ & $I(13)$ & & $2(33)$ & $5(\mathrm{II})$ & \\
\hline \multicolumn{8}{|c|}{ Comorbid health concerns, $\mathbf{N}(\%)$} \\
\hline $\mathrm{CHF}$ & $5(9)$ & $4(9)$ & $I(13)$ & 0.75 & $0(0)$ & $5(\mathrm{II})$ & 0.4 \\
\hline CVD & $8(15)$ & $8(18)$ & $0(0)$ & 0.2 & $3(50)$ & $5(11)$ & 0.011 \\
\hline Diabetes & $13(25)$ & $10(22)$ & $3(38)$ & 0.35 & $\mathrm{I}(\mathrm{I7})$ & $12(26)$ & 0.63 \\
\hline Cancer & $6(\mathrm{II})$ & $5(I I)$ & $I(13)$ & 0.91 & $0(0)$ & $6(13)$ & 0.35 \\
\hline
\end{tabular}

Abbreviations: $\mathrm{CHF}$, congestive heart failure; $\mathrm{CVD}$, coronary vascular disease. 
Table 2 Differences between groups for Walk Score ${ }^{\circledR}$, SF-12, and DASI in 53 older adults

\begin{tabular}{|c|c|c|c|c|c|c|c|}
\hline \multirow[t]{2}{*}{ Variable: walk a block? } & \multirow{2}{*}{$\begin{array}{l}\text { Overall } \\
(N=53)\end{array}$} & \multirow{2}{*}{$\frac{\text { Walk block }}{(N=47)}$} & \multirow{2}{*}{$\frac{\text { Did not walk }}{(N=6)}$} & \multirow[t]{2}{*}{$P$ value } & \multirow{2}{*}{$\frac{\text { Never bike }}{(N=45)}$} & \multirow{2}{*}{$\begin{array}{l}\text { Bike } \\
(N=8)\end{array}$} & \multirow[t]{2}{*}{$P$ value } \\
\hline & & & & & & & \\
\hline Walk score & $38.98 \pm 28.13$ & $38.85 \pm 27.44$ & $40 \pm 36.08$ & 0.93 & $39.44 \pm 28.49$ & $36.38 \pm 27.68$ & 0.78 \\
\hline $\begin{array}{l}\text { SF-12 mental scale: norm } \\
\text { mean }=50, S D=10\end{array}$ & $55.4 \pm 6.66$ & $56.07 \pm 6.52$ & $49.88 \pm 5.55$ & 0.048 & $55.38 \pm 6.74$ & $55.54 \pm 6.63$ & 0.96 \\
\hline $\begin{array}{l}\text { SF-1 } 2 \text { physical scale: norm } \\
\text { mean }=50, S D=10\end{array}$ & $40.89 \pm 11.54$ & $42.08 \pm 11.18$ & $31.09 \pm 10.66$ & 0.043 & $41.26 \pm 11.88$ & $38.45 \pm 9.45$ & 0.58 \\
\hline DASI & $35.92 \pm 15.44$ & $38.44 \pm 13.38$ & $16.18 \pm 17.49$ & $<0.001$ & $35.62 \pm|4.9|$ & $37.61 \pm 19.23$ & 0.74 \\
\hline
\end{tabular}

Abbreviations: DASI, Duke Status Activity Index; SF- I2, I2-item short-form survey; SD, standard deviation.

not different between those who walked or did not. These findings are noted in Table 2. The secondary evaluation of the relationship between DASI scores and Walk Score ${ }^{\circledR}$ did not reveal a relationship $\left(\mathrm{r}^{2}=0.011 ; P=0.44\right)$. The scatterplot is shown in Figure 2. In regressing Charlson index score to DASI score, there was a decrease of 2.5 in the DASI for each one point increase in the Charlson index $\left(\mathrm{r}^{2}=0.16 ; P=0.003\right)$ (Figure 3$)$. In a similar fashion, regressing age against the DASI resulted in a 1.4 point decrease in DASI score for each year increase from ages $70-85$ years $\left(r^{2}=0.17 ; P=0.002\right)$ (Figure 4$)$.

\section{Discussion}

In our study, there was a lack of a relationship between the Walk Score ${ }^{\circledR}$ and walking and biking in this older population. In all groups and especially in the older population, health care providers often recommend physical activity as a primary means of controlling many chronic diseases such as diabetes, heart disease, and chronic obstructive pulmonary disease. Previous surveys of the population of Olmsted County indicate that about half of the residents aged over 70 years exercise for 30 minutes on most days of the week. ${ }^{2}$ People can walk or bike as a primary means of transportation as one method to increase physical activity.

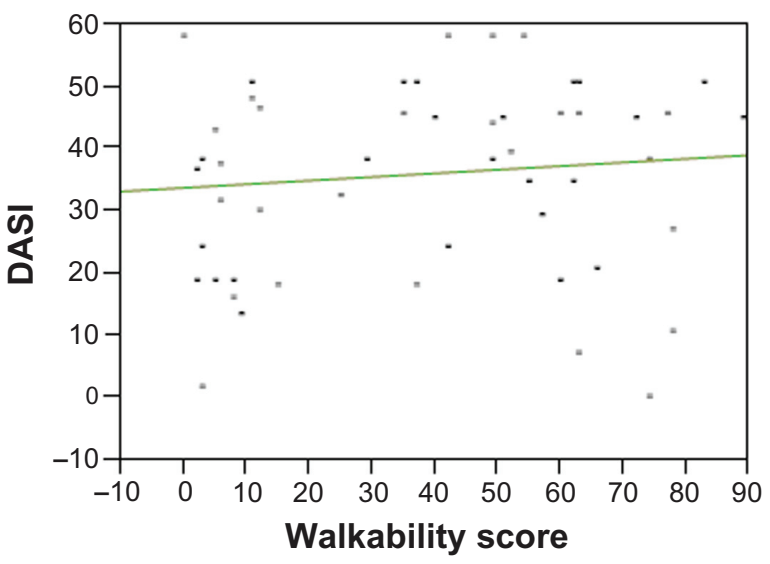

Figure 2 Linear regression of Walkability versus Duke Activity Status Index (DASI) score in 53 adults.
Practically, there is a need for amenities to be close for active transportation to be viable for older adults. The Walk Score ${ }^{\circledR}$ in the overall cohort was $38.98 \pm 28.13$, indicating that the overall cohort lived in areas that were not generally conducive to walking or biking. In the group that walked, there was no difference in the Walk Score ${ }^{\circledR}$ $(38.85 \pm 27.44)$ compared to those participants that did not walk $(40.0 \pm 36.08)$. A similar lack of significance was noted with the bicycle use (11\%). Using the DASI as a marker for functional status, there was no association between the DASI score and Walk Score ${ }^{\circledR}$.

One potential reason for this lack of association between the Walk Score ${ }^{\circledR}$ and walking or biking involved the general environment. The participants lived in areas that had low Walk Score ${ }^{\circledR}$ overall. Many senior apartments and assisted living facilities were built at the edge of town, away from retail shops or other amenities. The low overall Walk Score ${ }^{\circledR}$ may reflect the lower population density of 1956 people/ square mile in Rochester, MN. ${ }^{1}$ Thus, the community as a whole may be designed for car transportation rather than walking. There may be specific, environmental issues which facilitate or hinder bicycle use. The lack of an association between walking and biking and Walk Score ${ }^{\circledR}$ may reflect the lack of infrastructure for bike use or sidewalks for walking.

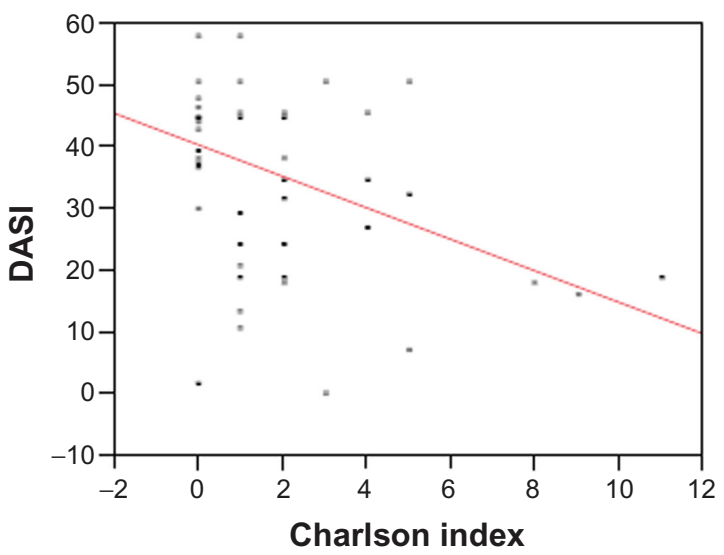

Figure 3 Linear regression of Charlson Index versus Duke Activity Status Index (DASI) score in 53 adults. 


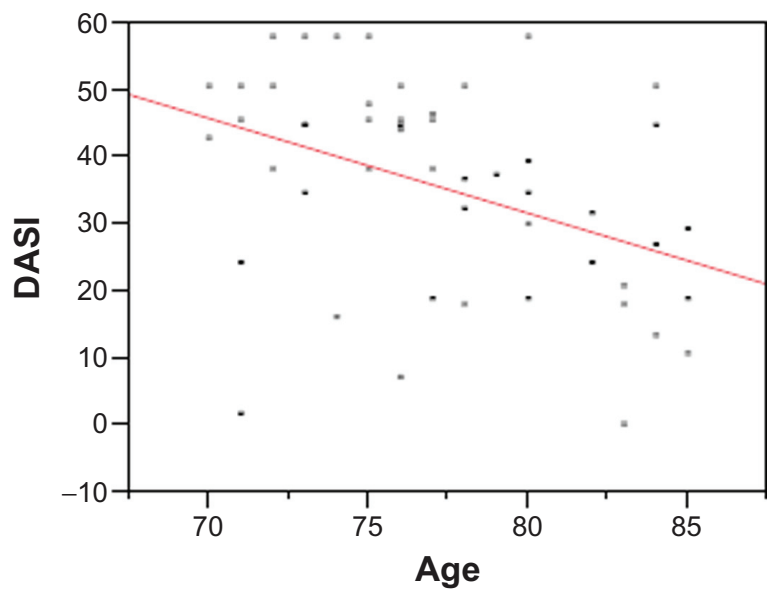

Figure 4 Linear regression of age versus Duke Activity Status Index (DASI) score in 53 adults.

In previous studies of younger people, the effect of the built environment on cycling has been lower than hypothesized. ${ }^{14}$ The Walk Score ${ }^{\circledR}$ uses a direct "as the crow flies" method of calculating a score; and does not take into account the quality or accessibility of sidewalks, bike lanes, or traffic. Thus, one does not know the quality of the infrastructure. Even using the best case scenario, amenities are far away. Lastly, people may walk or bike for recreation and may not take into account the proximity of amenities. All of the above issues may contribute to the lack of a relationship between the Walk Score ${ }^{\circledR}$ and walking or biking.

We did find a relationship between age and functional status, as noted by the decrease in DASI scores with an increase in age. These findings would be expected given national surveys on age and physical activity. ${ }^{15}$ In the present study, as the older cohort aged, there was a decrease in the DASI score by 1.4 points for each additional year. Physical activity tends to decline with advancing age and in particular ages over 65 years. ${ }^{16}$ It appears that age had a much bigger impact on walking or biking than the physical environment in our study. Aging-associated sarcopenia may be the most important component to impact walking or biking. ${ }^{17}$

Comorbid health conditions, as measured by the Charlson index, also played a role with walking or biking. Comorbid health conditions are associated with a frail state, which reflects an accumulation of functional deficits. ${ }^{18}$ Thus, an increase in comorbid conditions can lead to an increase in frailty. The phenotype of frailty involves weight loss, decreased energy, fatigue, weakness, and slow gait speed. ${ }^{19}$ We found a decrease of 2.5 points of the DASI score for each one point increase in the Charlson index. Comorbid illness seems to play an important role with functional status and with activity. In a previous study of older participants, investigators found a decrease in physical activity and worsened outcomes, with an increase in the Charlson index. ${ }^{20}$ Thus, as participants develop more illnesses, they tend to have a decreased functional status. Practically, the influences of age and comorbid health conditions play a bigger role in functional status and walking and biking than the built environment. Unfortunately, age is not amenable to change, whereas the built environment can be changed to facilitate walking and biking.

This study has numerous strengths and some weaknesses. The survey return rate of $43.8 \%$ is an adequate return rate in those that received the survey. Unfortunately, almost half of the surveys could not be used because people moved or died. The expectation of over 100 surveys was not achieved. Despite the lower number of surveys, the results still point to the greater importance of age and comorbid health status, compared to the Walk Score ${ }^{\circledR}$ in Rochester, MN. Using self-report to reflect activity status may not adequately measure the activity of the participants in the study. There may be bias in the self-report questionnaire compared to monitoring or measuring activity directly. People may underestimate how much activity they do. The overall cohort had low Walk Score ${ }^{\circledR}$, which likely limited the impact of the environment on walking. There are some limitations to the generalizability of the information from this survey. The biggest limitation involves the community in which the older person lives. In smaller cities in midwestern United States, this study likely has some generalizability. To other countries, dense urban areas, and small rural communities, the results may differ greatly. There could still be a profound role of age and comorbid health status in these groups. There may have been some return bias in those subjects who returned the surveys, compared to those who did not. All efforts were attempted to increase the response rate to reduce this type of bias. Recall bias is certainly possible in this older population, and there might be potential for forgetting or minimizing walking or biking.

\section{Conclusion}

The hypothesis that there would be a relationship between the built environment, as measured by the Walk Score ${ }^{\circledR}$, and the frequency of walking in an older adult population in Rochester, MN, is not supported by the findings of this study. Functional status did decline as subjects aged or had higher comorbid medical conditions. This study highlights the importance of age and health as the primary components of walking and biking. This unique study also outlined the challenges that some older adults face as they live in areas that are not accessible to amenities. Different cities and 
towns will have different barriers to walking and biking in older adults. Future studies should incorporate the use of local knowledge and geographic information systems data in determining a walkability scoring system. Using local knowledge and data may bear out relationships not revealed through use of the Walk Score ${ }^{\circledR}$.

\section{Acknowledgments/disclosures}

We acknowledge the support of Primary Care Internal Medicine at Mayo Clinic as the primary funding source for this survey. We acknowledge the help of Betty Wirt as the study coordinator for this study. We also acknowledge the Department of Internal Medicine for supporting the statistical support for the study. The author reports no conflicts of interest in this work. We also acknowledge Jody Clikeman for manuscript preparation.

\section{References}

1. Bureau C. Census Information, Olmsted County, MN. 2010. Available from: http://quickfacts.census.gov/qfd/states/27/27109.html. Accessed on November 16, 2011.

2. Kottke TE, Brekke MJ, Brekke LN, et al. The CardioVision 2020 baseline community report card. Mayo Clin Proc. 2000;75(11): $1153-1159$.

3. Wang Z, Lee C. Site and neighborhood environments for walking among older adults. Health Place. 2010;16(6):1268-1279.

4. Richards R, Murdoch L, Reeder AI, Amun QT. Political activity for physical activity: health advocacy for active transport. Int J Behav Nutr Phys Act. 2011;8:52.

5. Sundquist K, Eriksson U, Kawakami N, Skog L, Ohlsson H, Arvidsson D. Neighborhood walkability, physical activity, and walking behavior: the Swedish Neighborhood and Physical Activity (SNAP) study. Soc Sci Med. 2011;72(8):1266-1273.

6. Owen N, Cerin E, Leslie E, et al. Neighborhood walkability and the walking behavior of Australian adults. Am J Prev Med. 2007;33(5): 387-395.
7. Kruger J, Ham SA, Prohaska TR. Behavioral risk factors associated with overweight and obesity among older adults: the 2005 National Health Interview Survey. Prev Chronic Dis. 2009;6(1):A14.

8. Association WM. Declaration of Helsinki: Ethical Principles for Medical Research Involving Human Subjects. Paper presented at WMA 18th General Assembly, 1964; Helsinki, Finland.

9. Hlatky MA, Boineau RE, Higginbotham MB, et al. A brief selfadministered questionnaire to determine functional capacity (the Duke Activity Status Index). Am J Cardiol. 1989;64(10):651-654.

10. Walk Score ${ }^{\circledR}$. [Homepage on the Internet]. 2012. Available from: http:// www.walkscore.com/. Accessed on November 16, 2011.

11. Duncan DT, Aldstadt J, Whalen J, Melly SJ, Gortmaker SL. Validation of walk score for estimating neighborhood walkability: an analysis of four US metropolitan areas. Int J Environ Res Public Health. 2011; 8(11):4160-4179.

12. Charlson ME, Pompei P, Ales KL, MacKenzie CR. A new method of classifying prognostic comorbidity in longitudinal studies: development and validation. J Chronic Dis. 1987;40(5):373-383.

13. Ware J Jr, Kosinski M, Keller SD. A 12-Item Short-Form Health Survey: construction of scales and preliminary tests of reliability and validity. Med Care. 1996;34(3):220-233.

14. Moudon AV, Lee C, Cheadle AD, et al. Cycling and the built environment, a US perspective. Transp Res Part D Transp Environ. 2005;10(3):245-261.

15. Santos A, McGuckin N, Nakamoto H, Gray D, Liss S. Summary of Travel Trends: 2009 National Household Travel Survey. Washington, DC: US Department of Transportation; 2011.

16. Belanger M, Townsend N, Foster C. Age-related differences in physical activity profiles of English adults. Prev Med. 2011;52(3-4): 247-249.

17. Morley JE, Abbatecola AM, Argiles JM, et al. Sarcopenia with limited mobility: an international consensus. JAm Med Dir Assoc. 2011;12(6): 403-409.

18. Rockwood K, Mitnitski A. Frailty in relation to the accumulation of deficits. J Gerontol A Biol Sci Med Sci. 2007;62(7):722-727.

19. Fried LP, Tangen CM, Walston J, et al. Frailty in older adults: evidence for a phenotype. J Gerontol A Biol Sci Med Sci. 2001;56(3): M146-M156.

20. Covinsky KE, Justice AC, Rosenthal GE, Palmer RM, Landefeld CS. Measuring prognosis and case mix in hospitalized elders. The importance of functional status. J Gen Intern Med. 1997;12(4): 203-208.
Risk Management and Healthcare Policy

\section{Publish your work in this journal}

Risk Management and Healthcare Policy is an international, peerreviewed, open access journal focusing on all aspects of public health, policy, and preventative measures to promote good health and improve morbidity and mortality in the population. The journal welcomes submitted papers covering original research, basic science, clinical \& epidemio-

\section{Dovepress}

logical studies, reviews and evaluations, guidelines, expert opinion and commentary, case reports and extended reports. The manuscript management system is completely online and includes a very quick and fair peerreview system, which is all easy to use. Visit http://www.dovepress.com/ testimonials.php to read real quotes from published authors. 